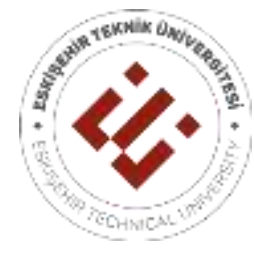

ESKISSEHIR TECHNICAL UNIVERSITY JOURNAL OF SCIENCE AND TECHNOLOGY A- APPLIED SCIENCES AND ENGINEERING

8th International Fiber and Polymer Research Symposium

(8th ULPAS) - Special Issue 2021

2021, Vol.22 pp. 70-84, DOI:10.18038/estubtda.983329

\title{
DEVELOPMENT AND CHARACTERIZATION OF VITAMIN B 9 - ELECTROSPRAYED NON-WOVEN SURFACES FOR WOUND HEALING APPLICATIONS
}

\author{
Fatma Nur PARIN ${ }^{1}{ }^{*}$ (D), Kenan YILDIRIM ${ }^{1}$ (D), Gökçe TANER ${ }^{2}$ (D), Elife KILDALI ${ }^{2}$ (i) \\ ${ }^{1}$ Department of Polymer Materials Engineering, Faculty of Engineering and Natural Sciences, Bursa Technical University, \\ Bursa, Turkey \\ ${ }^{2}$ Department of Bioengineering, Faculty of Engineering and Natural Sciences, Bursa Technical University, Bursa, Turkey
}

\begin{abstract}
In this study, novel wound dressing materials based on non-woven (NW) surfaces were developed using the electrospraying (e-spraying) process. Polyester spun-bond (PET SPB), polypropylene spun-bond (PP SPB), and polypropylene melt-blown (PP MB) surfaces used as matrix, and folic acid (FA), vitamin B 9weresprayed on these surfaces. The resulting NW fabrics with the same FA content were investigated in terms of physical, morphological, thermal, wettability properties.Scanning Electron Microscopy and (SEM) and Fourier Transform Infrared (FT-IR) spectroscopy results showed the formation of physical interaction between NWs and FA.Notably, FA was successfully deposited onto NWs with average fiber diameters from $2.6 \mu \mathrm{m}$ to $23.11 \mu \mathrm{m}$. According to the thermogravimetric analysis (TGA),FA loaded-PP SPB has enhanced thermal stability compared to pure one (PP SPB). The FA-loaded surfaces have a hydrophobic property with contact angles values more than $>90^{\circ}$. The in-vitro release was carried out by UV-Vis within the 8 hour-period phosphate buffer saline (pH 7.2). The results indicated that FA-loaded surfaces have a fast release behaviour. The total FA release amounts of the FA-loaded PET SBP, PP SPB and PP MB NWs were found as 22.8, 17.1, and $17.5 \mathrm{ppm}$. Moreover, the biocompatibility of all resulting NW surfaces was assessed by 3-(4,5-dimethylthiazol-2-yl)-2,5-diphenyltetrazolium bromide (MTT) and neutral red uptake (NRU) cytotoxicity tests in L929 cell lines.The obtained NWs are biocompatible and non-toxic material, except PET SPBsFA.The study indicated that FA-loaded NWs can be potential candidates for wound healing applications.
\end{abstract}

Keywords: Non-woven surfaces, Wound healing, Folic acid, Contact angle, Thermal analysis

\section{INTRODUCTION}

Cell proliferation, migration, reepithelization, and tissue remodelling are all part of the wound healing process that is assisted by complex interactions between growth factors, extracellular matrix, bioactive agents, and cells $[1,2]$. B-vitamins are regenerative agents, which are playing an essential role in many bodily functions as cofactors for enzymes. Especially, due to the epigenetic role of folic acid $\left(\mathrm{C}_{19} \mathrm{H}_{19} \mathrm{~N}_{7} \mathrm{O}_{6}\right)$ in many human metabolic activity, it is an important member of B-complex vitamins, which is known as $\mathrm{B}_{9}$ vitamin, plays a crucial role in the maintenance of many metabolic functional processes in the body, such as cell growth, and development, synthesis of nucleic acids and metabolism of many amino acids [3, 4]. Folic acid (FA) is being studied due to its role in the synthesis of both building-block molecules and their effects on differentiation. It is one of the most important factors in tissue regeneration and repair [2].

There have previously been reported in various studies that folic acid can promote cell growth when added to polymer forms (in cream, fiber, microcapsule, micro/hydrogel, and even neat powder, etc.). In this context, Duman et al. (2018) reported that folinic acid enhances wound healing in rats. Fischer et al. investigated the effects of topical folic acid and creatine-containing formulations on skin firmness on collagen gene expression [5]. Moreover, in endothelial cell line proliferation experiments, the effect of folic acid on cell proliferation at different concentrations was investigated by in vitro proliferation experiments [2]. In the study that wound healing process simulated by software

*Corresponding Author:nur.parin@btu.edu.tr

Received: 16.08.2021 Published: 30.11.2021 
analysisincreased cell proliferation was reported compared to the control group by almost $40 \%$ at the end of $48 \mathrm{~h}$. In our previous study, cytocompatibility assays results showed folic acid-loaded hydrophilic fibers have no toxicity and neat folic acid improved cell generation by nearly $177 \%$ [6]. It is contrary to the restriction of the utilization of folic acid in pure form, Pagano et al. (2019) synthesized folic acid-based emulgels and MTT tests have indicated cell viability over $100 \%$ [7].Furthermore, Zhao et al. (2018) indicated folic acid can accelerate collagen formation in diabetic wounds [8].In a similar study, Khan et al. asserted folic acid could be a potential candidate for the oral mucosal wound healing process [9].

Camacho et al. (2019) createdcopper-alginate hydrogels containing folic acid. The slow folic acid release observed only at $\mathrm{pH}>5$, particularly in simulated intestinal conditions, and these organometallic hydrogels performed as a gastro-resistant material ( $\mathrm{pH} \mathrm{8.2).} \mathrm{Furthermore,} \mathrm{with} \mathrm{a} \mathrm{zero-}$ order $\mathrm{k}$, the successful compounds showed greater release in alkaline medium ( $>80 \mathrm{ppm}$ ) compared to acidic media (pH 5.4) ( 8 ppm) [10].

Mallakpour and Hatami (2020) preparedchitosan nanocomposite films containing folic acid for use as bone and tooth additives in tissue engineering [11]. Contact angle measurements showed that the produced films had improved wettability and were more hydrophilic. Furthermore, the bioactivity of these NC films by soaking them in simulated body fluid (SBF, pH 7.4), and the $\mathrm{pH}$ changes for this solution were observed for 1 month. In a similar study, Acevedo-Fani et al. (2018) developed folic acid/polysaccharide-based nanolaminate films [12]. With the addition of folic acid, the structure of the nanolaminates improved, resulting in homogeneous and smooth layers. At $\mathrm{pH} 3$, only $22 \%$ of the FA was released from the films after 7 hours, while at $\mathrm{pH} \mathrm{7,} \mathrm{over} 100 \%$ of the FA was released. This is due to folic acid becoming entrapped in nanolaminates due to its poor performance.

Fonseca et al. (2020) did a study on improving folic acid bioavailability. The release behavior of nanofibers containing various amounts of FA $(5,10$, and $15 \%)$ were obtained using starch as a matrix. Although the diameters of nanofibers produced below $100 \mathrm{~nm}$ did not vary much, some beads in FAloaded fibers was detected [13].

A study on PVP/dextran octadecyl amine/montmorillonite/VB 9 conjugate nanofibers have been fabricated by Şimşek et al. (2016). The nanofibers' cytotoxicity tests indicated that $\mathrm{VB}_{9}$ had no negative effects on Vero cells (liver cells), suggesting that these fibers might be a game-changer in cancer research and tissue engineering applications [14].

Electrospraying (e-spraying), one of the electrohydrodynamic atomization (EHDA) methods, in which low-viscosity liquids through electrical forces are coated with a carrier material to form regular structures in sub-micron or nanoscale sizes by an electric field $[15,16]$. It is more advantageous than other methods such as spray drying, coacervation, and emulsion with the formation of nonagglomerated capsule structures with high active ingredient content with better size distribution without high temperature, pressure or toxic solvent. Hydrophobic and hydrophilic bioactive molecules, or therapeutics can be encapsulated into polymer matrices with almost $100 \%$ efficiency by this method [17].

The current study is focused on the development of FA-loaded fibrous structures via the electrospraying method. As distinct from the previous studies, there is no report on the electrospraying of FA onto melt-blown and spun-bond surfaces. Therefore, the optimum amount of FA was studied to investigate electrospraying capacity, in vitro release in PBS media, and cell viability, and the availability of the wound applications was evaluated. Moreover, a detailed characterization study of the resulting surfaces was carried out by performing Scanning Electron Microscopy and (SEM) Fourier Transform Infrared (FT-IR) spectroscopy, thermogravimetric analysis (TGA), and contact 
angle test. TGA curves indicated that FA inhibits the degradation of the FA-loaded PP SPB and acts as an antioxidant at high temperatures. Overall, it has been suggested that the obtained surfaces can be used for wound healing applications.

\section{EXPERIMENTAL}

\subsection{Material}

In this study, PET spun-bond (SPB), PP spun-bond (SPB) and PP melt blown (MB) non-woven (NW) fabrics (Mogul Textile Company, Gaziantep/Turkey) were used. Folic acid $\left(\mathrm{C}_{19} \mathrm{H}_{19} \mathrm{~N}_{7} \mathrm{O}_{6}\right)$ for Biochemistry (98-102\% purity) was supplied from ChemSolute Company (Germany). The ethanol (99\% purity) was purchased from Sigma-Aldrich Chemical Company (USA). Phosphate buffer saline (PBS) tablets ( $\mathrm{pH}$ 7.2) were used for each in-vitro release study. The chemicals used in the MTT and NRU assay tests were purchased from the following suppliers; RPMI (Roswell Park Memorial Institute) 1640 medium, fetal bovine serum (FBS), penicillin-streptomycin, neutral red (NR) (3-amino7-dimethyl-amino-2-methylphenazine hydrochloride), 3-(4,5-dimethylthiazol-2-yl)-2,5diphenyltetrazolium bromide (MTT), trypan blue, ethanol from Sigma; dimethyl sulfoxide (DMSO) from Merck; Triton X-100, trypsin-EDTA, Dulbecco's phosphate-buffered saline (DPBS) from Gibco. In all experiments, distilled water was used.

\subsection{Method}

\subsubsection{Electrospraying of FA onto Non-woven Fabrics}

$10 \mathrm{~mL}$ folic acid $(22 \mathrm{mg})$ solution is prepared by mass with a mixture of $2 / 1$ ethyl alcohol-water solvents. The folic acid solution is sonicated in an ultrasonic homogenizer by applying $60 \%$ power for 30 min.It was then sprayed onto the surfaces of polyester spun-bond, PP spun-bond, and PP meltblown non-woven fabrics with $23 \mathrm{kV}$ electrical power, $100 \mathrm{~mm}$ distance (drum-to tip) and $150 \mathrm{rpm}$ drum speed at a flow rate ranging from 1-1.5 mL/h (Figure 1).

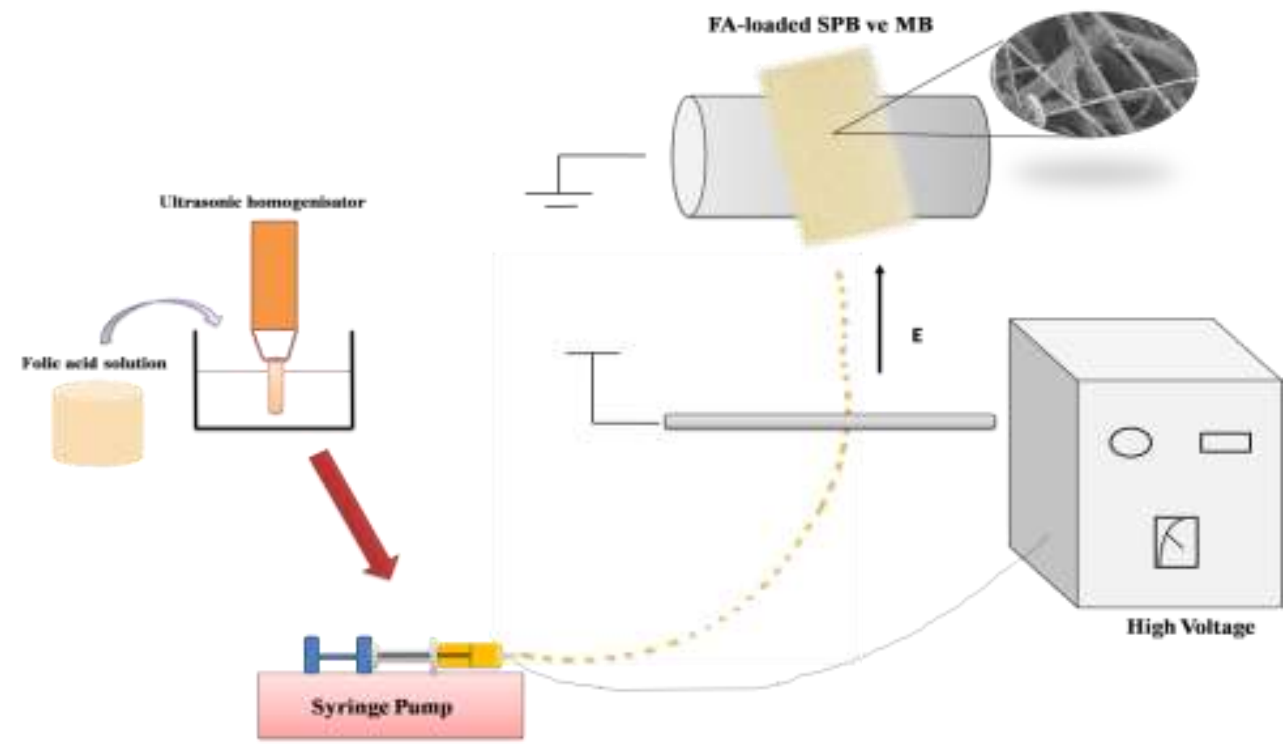

Figure 1. Schematic illustration of electrospraying method. 


\subsection{Characterization}

The microstructural analysis of all NWs was observed with Carl Zeiss/Gemini 300 Scanning Electron Microscope (SEM) (ZEISS Ltd.,Germany). Allsamples were coated with gold before analysis. The fiber diameters were measured by using Image $\mathrm{J}$ (version 1.520 software) by randomly selecting the diameters of 60 individual fibers for each sample. Average fiber diameters and fiber diameter histogram data were performed with Origin Pro 2018 software.

The physical analysis of all samples was analyzed by FT-IR Thermo Nicolet iS50 FT-IR (USA) spectrometer with an ATR adapter (Attenuated Total Reflectance) (Smart Orbit Diamond, USA).

The contact angles of the samples were measured with an automatic dispenser system Attension Theta Lite model optical tensiometer (Biolin Scientific, Gothenburg, Sweden).Contact angle measurementswere made by dropping $4 \mu \mathrm{L}$ distilled water to $2.5 \mathrm{~cm}$ x $2.5 \mathrm{~cm}$ samples. To calculate the average $\theta$ value, this analysis was repeated three times.

The thermogravimetric analysis (TGA) was realized under nitrogen atmosphere with $20^{\circ} \mathrm{C} \mathrm{min}{ }^{-1}$ heating rate, $30-600^{\circ} \mathrm{C}$ temperature range and then applied oxygen atmosphere with the same heating rate at $600-900^{\circ} \mathrm{C}$ temperature.

The pycnometer (Micromeritics-AccuPycII 1340) was used to measure the fiber volume using helium gas. Therefore, the porosities of non-wovens were measured by using the following equation:

$$
\text { Porosity }=\frac{\text { Volume (Vf) of NWs by Pycnometer }}{\text { Total Volume (Length } x \text { Widthx Thickness })}
$$

Thein-vitro release testswere applied to determine the FA release behaviour of NWs. The FA-release behavior of FA sprayed resulting non-wovens were studied in phosphate buffer solutions (PBS) at $\mathrm{pH}$ 7.2 by the total immersion method $[18,19] .20 \mathrm{~cm}^{2}$ of the samples were put into sealed glass tubes with each containing $100 \mathrm{~mL}$ of PBS, separately. Afterwards, the samples were placed in a shaking incubator at $37^{\circ} \mathrm{C}$ with stirring $120 \mathrm{rpm}$ to apply the release behaviour of the FA. About $3.5 \mathrm{~mL}$ of the samples were removed at the specified time intervals with the PBS and the corresponding absorbance value was determined with UV spectrophotometer (Scinco/NEOYSY 2000) at $\lambda_{\max }=282 \mathrm{~nm}$, which was the characteristic peak of FA. The FA concentration was obtained from the calibration curve of the model vitamin prepared with a FA solution of known concentrations in PBS (pH 7.2). The calibration curve was found to be $\mathrm{Y}=0.0639 \mathrm{X}+(0.0276)\left(\mathrm{R}^{2}=0.99997\right)$, where $\mathrm{X}$ is the concentration of FA $(\mathrm{mg} / \mathrm{L})$ and $\mathrm{Y}$ is the solution absorbance at $282 \mathrm{~nm}$ (linear range of $2.5-25 \mathrm{mg} / \mathrm{L}$ ) (Figure 2).

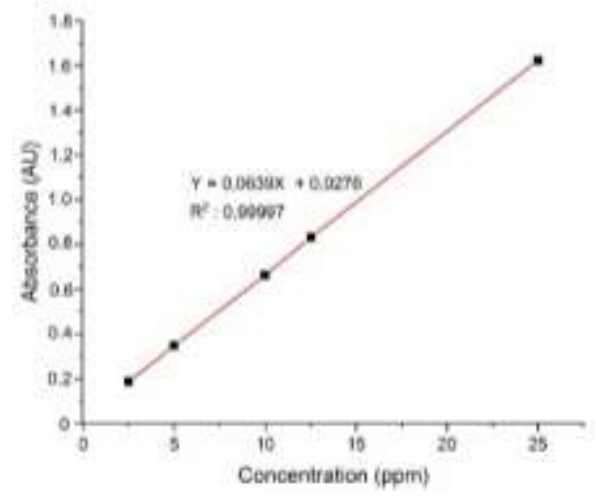

Figure 2. The calibration curve for FA in PBS. 
Two cytocompatibility tests, MTT and NRU havebeen carried out on all resulting NW surfaces by using L929 cell lines according to the ISO 10993-5.

\section{RESULTS AND DISCUSSION}

\subsection{Microstructural Analysis}

Figure 3-Figure 5 indicates the average fiber diameter distribution with SEM images of pure and FAsprayed NW surfaces. It is visible that pure NWs exhibit fibrillated smooth surface morphology, while FA particles are deposited on the surface of FA-sprayed NWs. The average fiber diameters of PET SPB and PET SPB-sFA were calculated as $16.91 \pm 3.28 \mu \mathrm{m}$ and $17.55 \pm 2.61 \mu \mathrm{m}$, respectively. PP MBs havemore irregular fiber diameters than, and average fiber diameters are also quite low $(2,59 \pm 1,14$ $\mu \mathrm{m})$. Similarly, Ekabutret al. (2019) found that a 5\% (w/v) amount of mangosteen extracts were coated on PP MB and some increase in fiber diameters were observed [20]. Jung et al. (2013) also produced an antibacterial filter and sophora extract (Sophora flavescens) was loaded on polyurethane filters having 10-20 mm via electrospraying method [21].
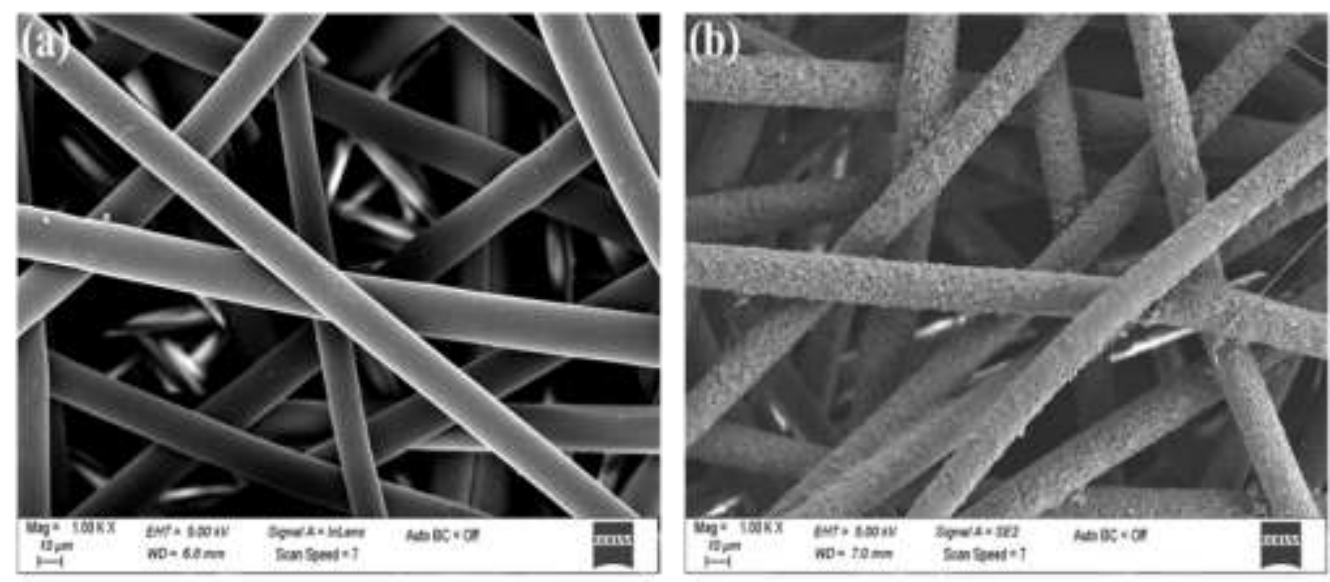

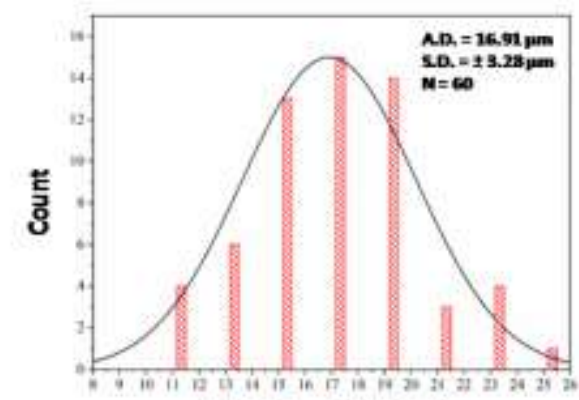

Fiber diameter (um)

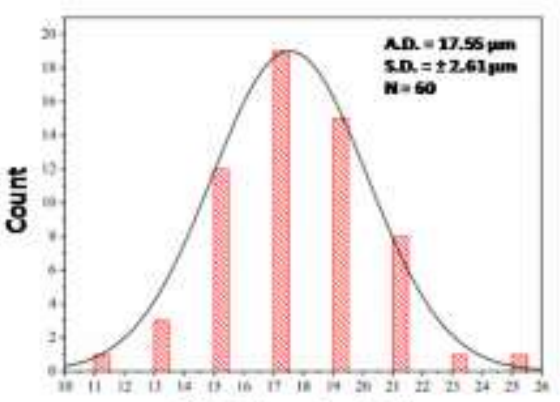

Fiber diameter ( $\mu \mathrm{m})$

Figure 3. SEM images of non-wovens (a) PET SPB (b) PET SPB-sFA (Magnification $1.00 \mathrm{kX}$, scale bar : $10 \mu \mathrm{m}$ ). 
Parın et al./ Eskişehir Technical Univ. J. of Sci. and Tech. A - Appl. Sci. and Eng. Vol. $22-2021$ 8th ULPAS - Special Issue 2021
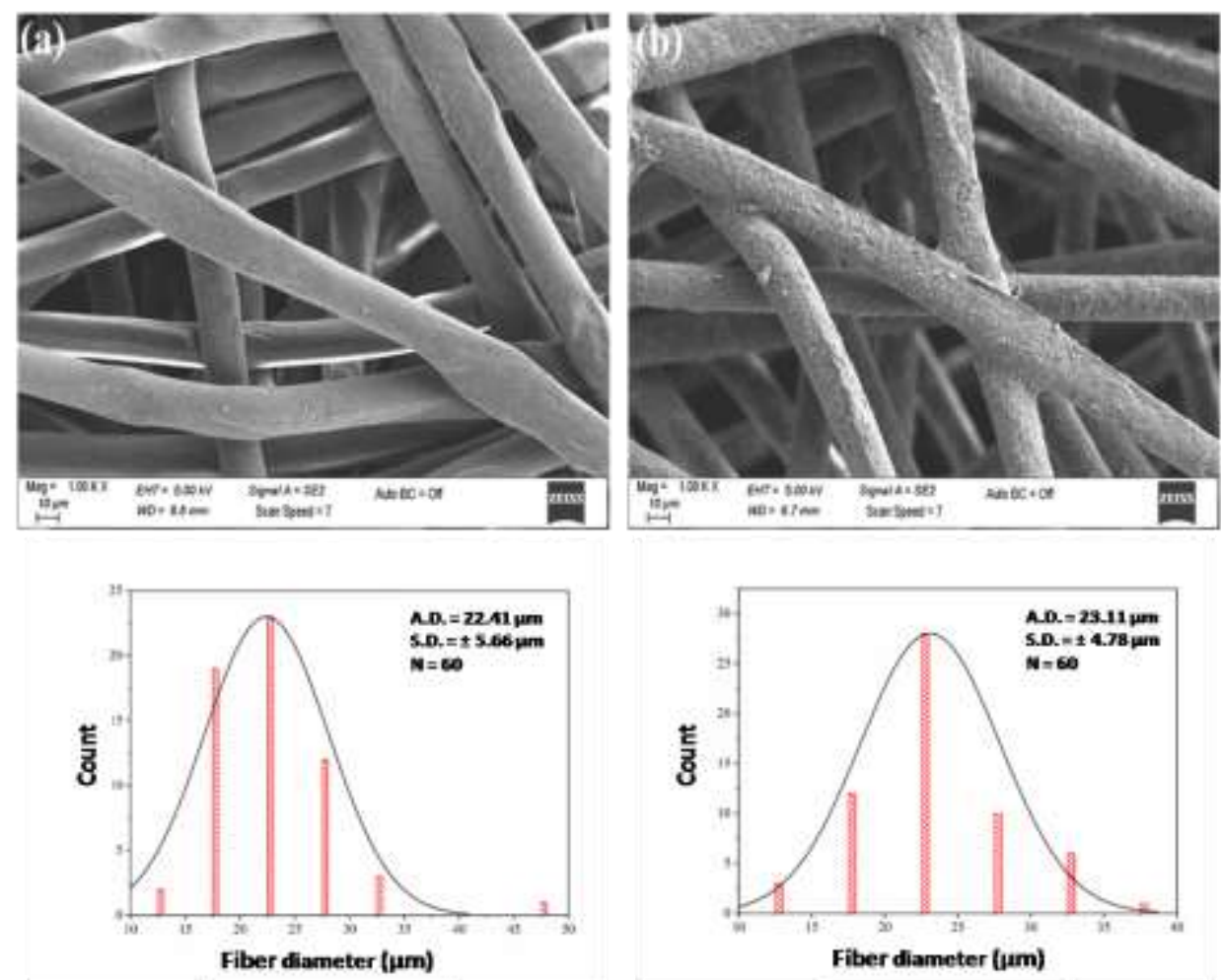

Figure 4. SEM images of non-wovens (a) PP SPB (b) PP SPB-sFA (Magnification $1.00 \mathrm{kX}$, scale bar : $10 \mu \mathrm{m}$ ).
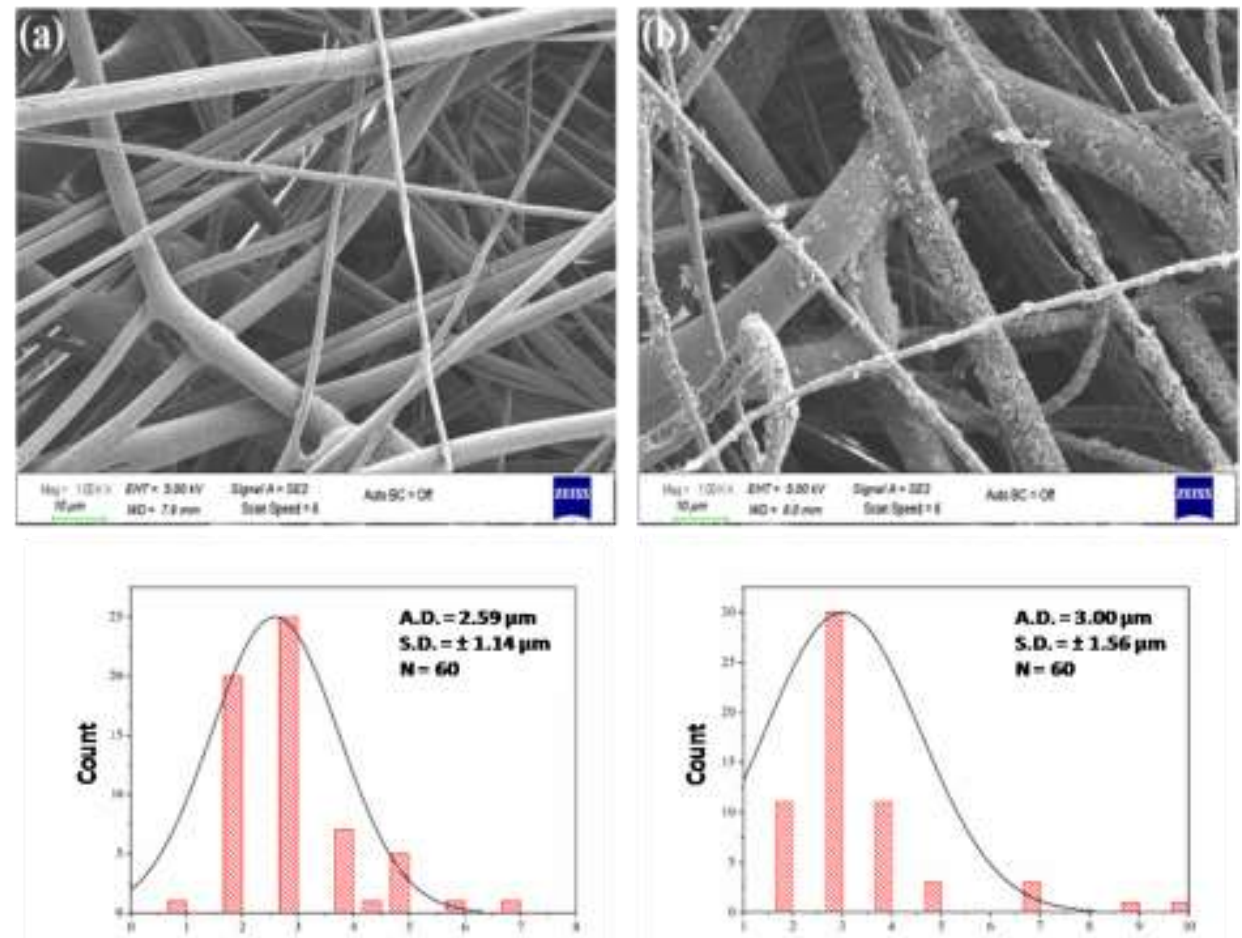

Fiber diameter ( $\mu \mathrm{m})$

Fiber diameter (um)

Figure 5. SEM images of non-wovens (a) PP MB (b) PP MB-sFA (Magnification $1.00 \mathrm{kX}$, scale bar : $10 \mu \mathrm{m}$ ). 


\subsection{Physical Structural Analysis}

FT-IR spectra of the pure non-woven surfaces and resulting FA-loaded nonwovens produced as a result of the electrospraying process are shown in Figure 6. The characteristic peaks of PET SPB show at $1712 \mathrm{~cm}^{-1}(-\mathrm{C}=\mathrm{O})$ and benzene ring at $1615 \mathrm{~cm}^{-1}$ [22]. The deformation vibration of the $\left(-\mathrm{CH}_{2}\right)$ group is $1340 \mathrm{~cm}^{-1}$ [23]. Another absorption peak at $1240 \mathrm{~cm}^{-1}$ is due to the (-C-O-C) stretching vibration. Characteristic IR absorption peaks of FA are confirmed in $3500-3100 \mathrm{~cm}^{-1}$. PP-based SPB non-woven surfaces indicate asymmetric and symmetric stretching vibration peaks at 2948, 2916 and $2836 \mathrm{~cm}^{-1}(-\mathrm{CH})$, respectively. The other peaks appear at $1455,1376 \mathrm{~cm}^{-1}$, and $840 \mathrm{~cm}^{-1}$ belong to ($\mathrm{CH}_{2}$ ) bending.

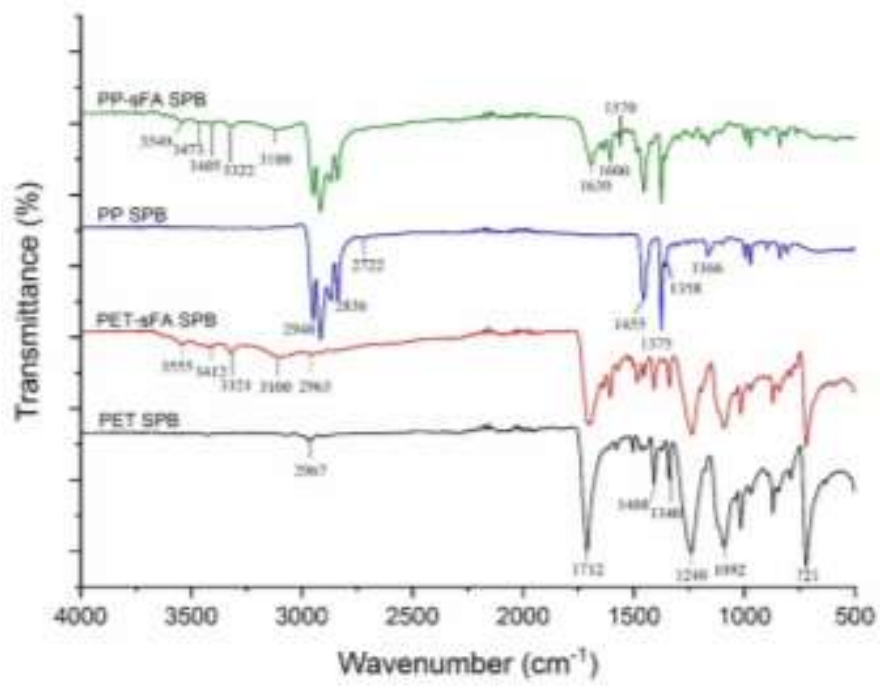

Figure 6. FT-IR spectra of non-woven surfaces.

\subsection{Contact Angle Analysis}

Wettability is related to the surface's hydrophobicity/hydrophilicity properties that acts an essential role to specify the wound healing management due to adhesion and cell proliferation between matrix/material and cells. Previous studies have suggested that the hydrophilicity of biomaterials is necessary for the cell healing process. However, these hydrophilic-based wound dressings can damage the wound and lead to secondary bleeding. Moreover, many studies have been reported hydrophobic surfaces inhibit bacterial adhesion [24].

The results of the contact angle measurements for water are given in Figure 8. According to the results, all NW surfaces have hydrophobic structure due to contact angle $>90^{\circ}$. For all FA-sprayed surfaces, loading of FA with hydrophilic structured on NWs reduced contact angle values. The measurements for water on PET SPB-sFA and PP MB-sFA were slightly similar, which were $102.6 \pm 4.1^{\circ}$ and $102.5 \pm 4^{\circ}$ respectively. 


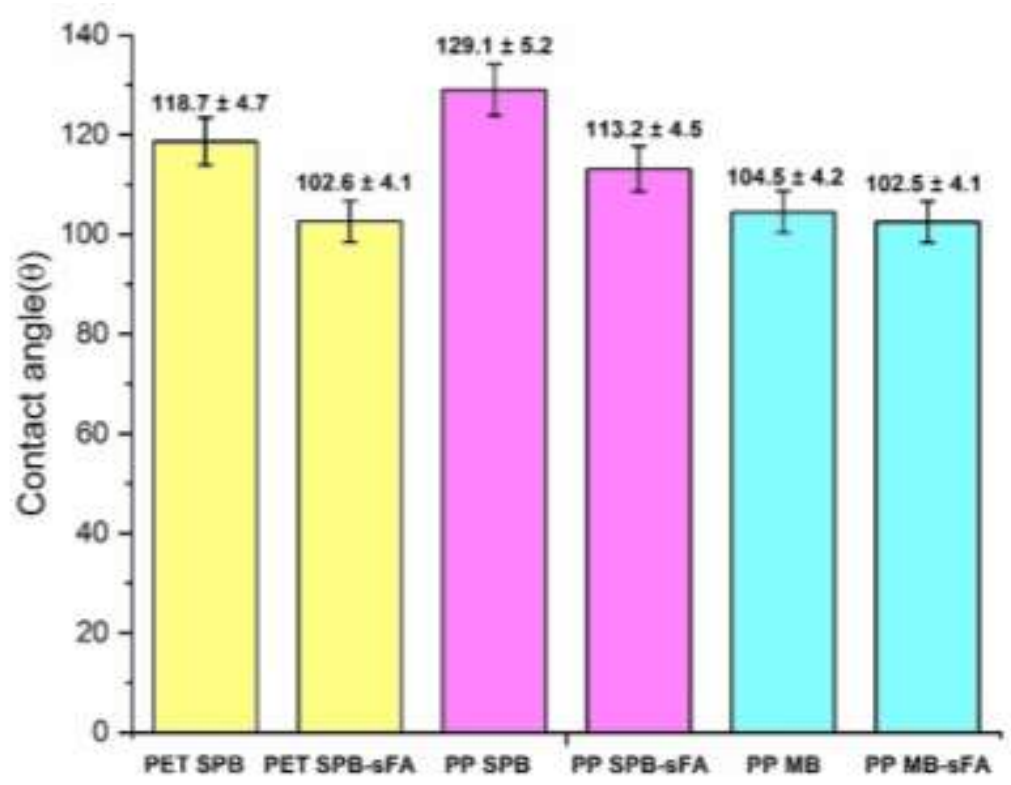

Figure 7. Contact angle values of non-woven surfaces.
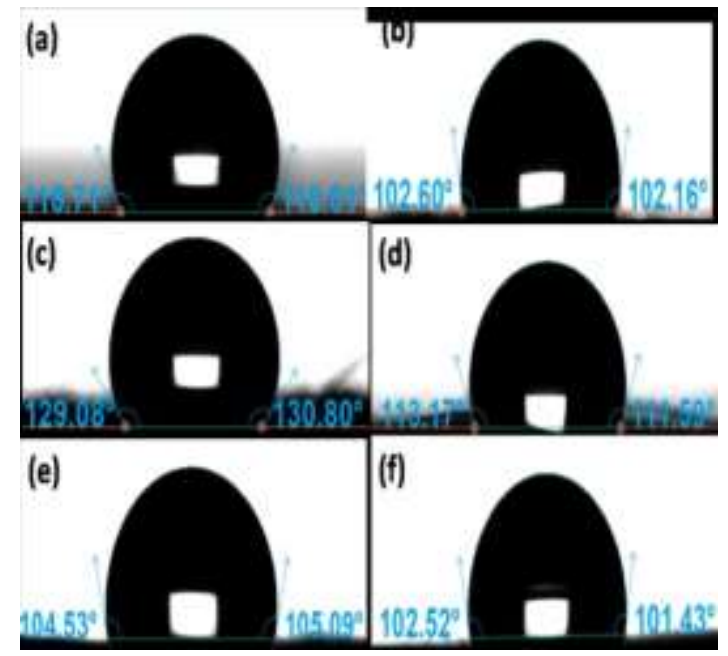

Figure 8. Contact angle images of water droplets on the surface of non-woven surfaces (a) PET SPB, (b) PET SPB-sFA, (c) PP SPB, (d) PP SPB-sFA, (e) PP MB, (f) PP MB-sFA.

\subsection{Thermal Analysis}

Figure 9 shows TGA thermograms for pure and FA-loaded PET and PP nonwoven (NW) surfaces. All samples showed weight loss in the range of $30-100{ }^{\circ} \mathrm{C}$ associated with moisture out of NWs. The first degradation step of pure PET SPB fabrics with two degradation steps has begun at about $380{ }^{\circ} \mathrm{C}$. In this step, the chain scissions of the ester bonds in the structure and the vinyl ester and carboxylic acid groups began to form and ended at $525{ }^{\circ} \mathrm{C}$ [25]. The second step is dominated by low molecular weight volatile components due to the complete breakage of the ester bonds with weight loss of 17.1 $\%$ about $590{ }^{\circ} \mathrm{C}$ to $630{ }^{\circ} \mathrm{C}$.

PET SPB-sFA showed weight loss up to $100^{\circ} \mathrm{C}$ related to moisture out of sample. After, the first degradation step, which started around $370{ }^{\circ} \mathrm{C}$, was completed at around $560{ }^{\circ} \mathrm{C}$. This step takes 
longer than a pure sample to confirm the degradation of the FA. The second (last) step $\left(590-640{ }^{\circ} \mathrm{C}\right)$ was related to the burning of the pyrolysis product which was formed during analysis in the $\mathrm{N}_{2}$ atmosphere.

For both PP SPB and PP SPB-sFA NWs, single-step degradation has been observed at $350-460{ }^{\circ} \mathrm{C}$ and $350-470{ }^{\circ} \mathrm{C}$, respectively.

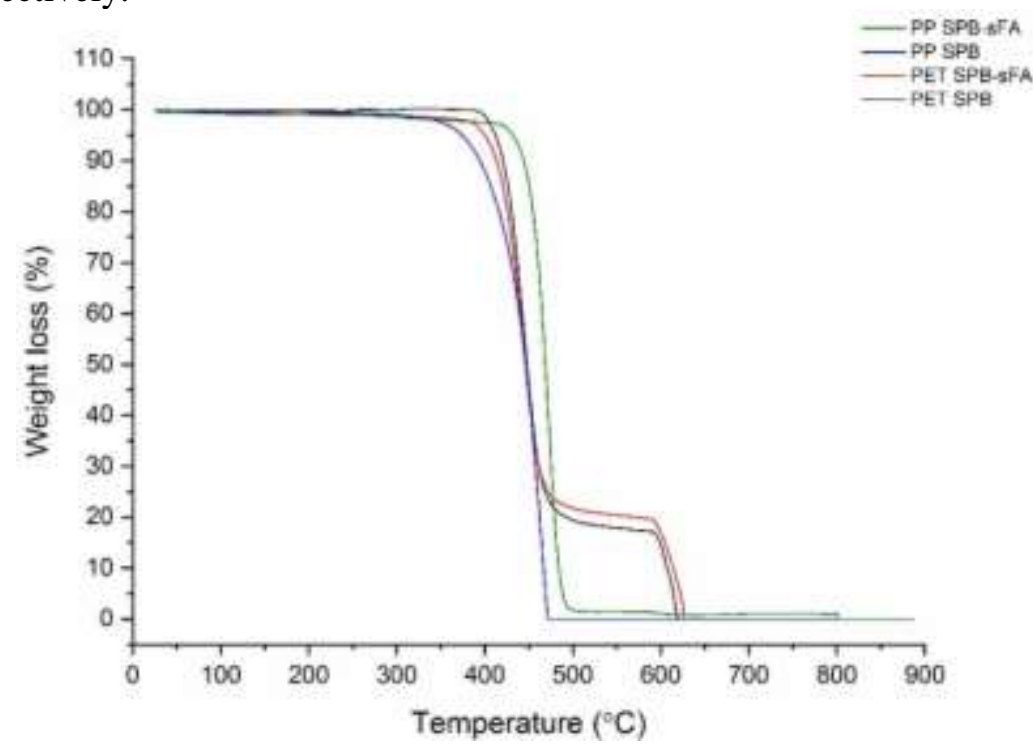

Figure 9. TGA thermograms of non-woven surfaces.

\subsection{Porosity Measurements}

High and low bulky non-woven fabrics have porosity values in the range of $90-99 \%$ and $45-80 \%$, respectively $[26,27]$. Table 1 shows the results of porosity by both the conventional method and pycnometer.

Table 1. Porosity results by pycnometer and conventional measurement.

\begin{tabular}{ccc}
\hline Sample ID & $\begin{array}{c}\text { Porosity by } \\
\text { pycnometer } \\
(\mathbf{1 - V} / \mathbf{V} / \mathbf{V}) * \mathbf{1 0 0}, \mathbf{( \% )}\end{array}$ & $\begin{array}{c}\text { Porosity by } \\
\text { conventional } \\
\text { measurement } \\
(\boldsymbol{\%})\end{array}$ \\
\hline PET SPB & 80.92 & 78.57 \\
PET SPB-sFA & 80.52 & 78.15 \\
PP SPB & 75.17 & 71.55 \\
PP SPB-sFA & 77.04 & 76.73 \\
PP MB & 81.58 & 81.69 \\
PP MB-sFA & 80.32 & 80.33 \\
\hline
\end{tabular}

The porosity of the non-woven surfaces is depends significantly on fiber orientation [28]. The random fiber orientation is clearly observed in SEM images. Generally, FA-loaded NW surfaces have almost the same porosity as pure NWs. This is due to the fact that FA desposited onto fiber structures, and this case does not directly effect the pore structure of the NWs. Further, the porosity phenomenon parallels to the fiber thicknesses. As FA was loaded onto NWs, fiber thicknesses increased slightly. In this study, the porosity values above $71 \%$ can be sufficient to increase cell migration in wound healing compared to our previous study [6]. 


\subsection{In-vitro Release Tests}

The release study of all FA-loaded NW surfaces was carried out over a period of 8 hours in PBS media (pH 7.2) at $37^{\circ} \mathrm{C}$ (Figure 10).

The release profiles show that the amount of cumulative FA releases are 22.8, 17.1, and $17.5 \mathrm{ppm}$ for PET SPB-sFA, PP SPB-sFA and PP MB-sFA, respectively after 8 hours. PET SPB-sFA exhibited an initial burst release profile in the first 4 minutes of analysis while PP SPB-sFA and PP MB-sFA showed burst release in the first 20 minutes. After burst release, there was an increase in the amount of release for PET SPBs. The reason for this is that surface peeling occurs in PET SPBs in a $\mathrm{pH} 7.2$ environment and can be explained by the dissolution of FA in this environment.

After sudden release, PP-based SPBs and MBs showed FA release reached a satisfaction point.

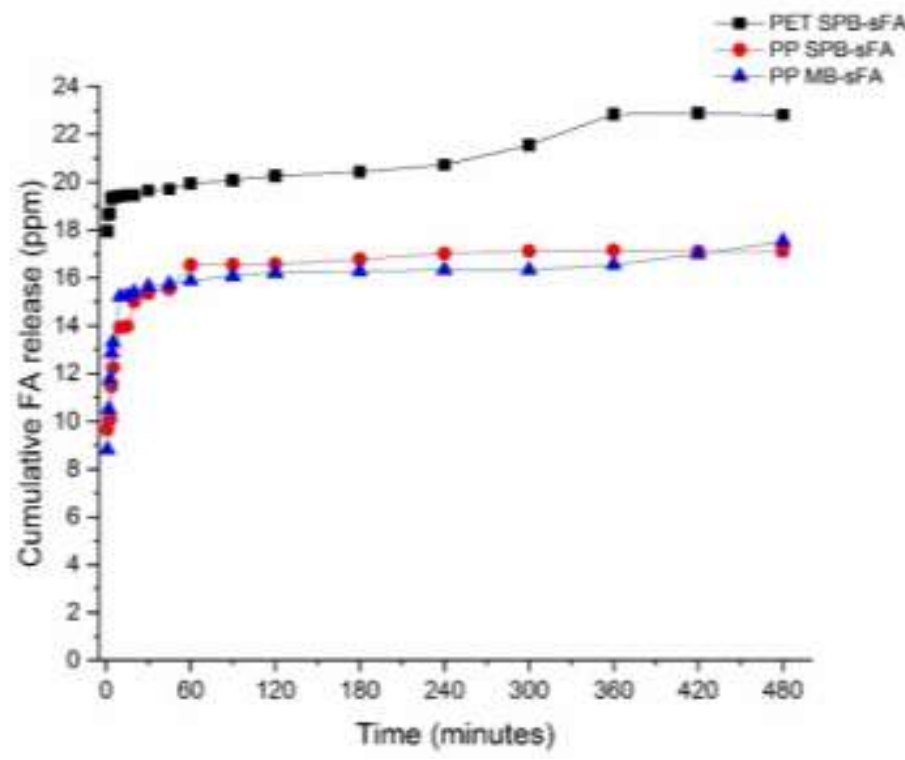

Figure 10. FA in vitro release profiles of NWs.

\subsection{Cytotoxic Effects of NWs by MTT and NRU Assay}

In this study, ISO 10993-12: 2009 standard was used for sample preparation of both references and novel NW materials. Both sides of samples arranged according to standards $\left(3 \mathrm{~cm}^{2} / \mathrm{mL}\right)$ were sterilized in a laminar flow cabinet for 1 hour under a UV lamp. $30 \mathrm{~cm}^{2}(6 \mathrm{~cm}$ x $5 \mathrm{~cm})$ sterile samples were put in a $10 \mathrm{~mL}$ culture medium (RPMI 1640 containing $1 \%$ Penicillin-Streptomycin, $10 \%$ serum) and kept at $37{ }^{\circ} \mathrm{C}$ for 72 hours to obtain extract solutions. At the end of the extraction period, samples were removed, and extract solutions were kept at $37{ }^{\circ} \mathrm{C}$ by the time cytotoxicity tests. The cytotoxic effect of the extract solutions of NWs was evaluated by both MTT and NRU assays in L929 cells. To determine the cytotoxicity, the effects of the $100 \%$ concentration of the original extract solutions of all reference and new NW samples on treated cells were compared with the negative control group without any chemicals. The average absorbance values and standard deviation values of living cells were calculated by averaging all the data obtained. In addition, cell viability in the control group was considered as $100 \%$, and living cell percentages were determined for all sample groups compared to the control. Results of the MTT and NRU tests are summarized in Figure 11. According to the results of cytotoxicity tests applied after $24 \mathrm{~h}$ of treatment in L929 cells, all reference and novel 
NWs accept PET SPB-sFA are cytocompatible since viability did not fall below $70 \%$. In this study, $50 \%$ diluted concentrations of all samples (data was not given in the figure) were also tested but there is a clear decrease in viability of cells treated with the original $100 \%$ extract concentration of PET SPB-sFA and cell death is concentration depended.

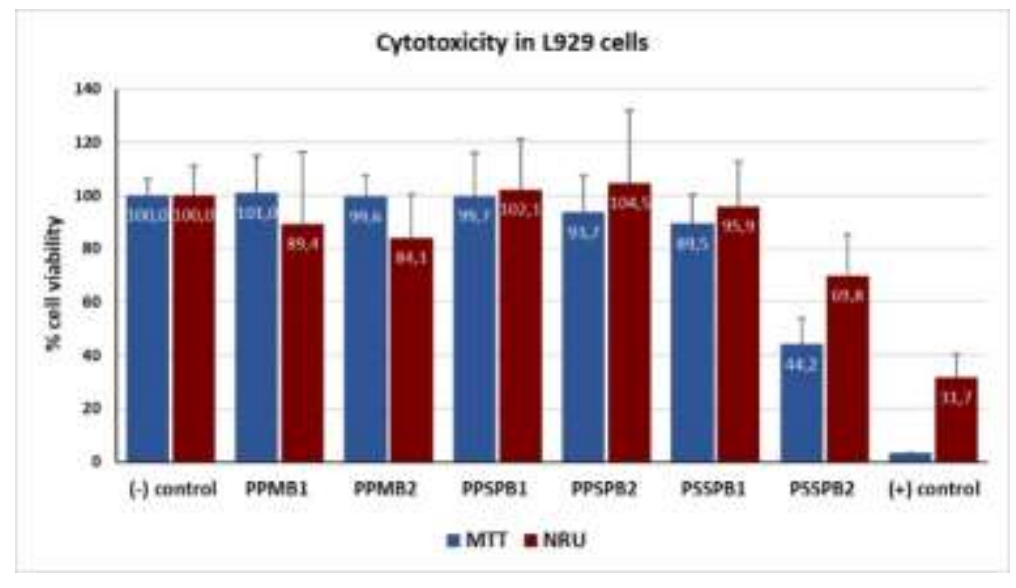

Figure 11. Effects of NW surfaces on cell viability of L929 cells by MTT and NRU assays.

It is important to evaluate the cytotoxic activity of novel biomaterials as a part of ISO 10993 protocols in terms of biocompatibility. In recent years, many methods have been developed to investigate cell viability and proliferation in cell culture. The most widely used of these are cytotoxicity assessments in 96-well plates which many samples can be analyzed quickly and easily in terms of cell viability [29]. In this study, cytocompatibility was determined with 3-(4,5-dimethylthiazol-2-yl)-2,5-diphenyl tetrazolium bromide (MTT) and neutral red uptake (NRU) cytotoxicity tests. MTT and NRU cytotoxicity assays are suitable biomarkers for evaluating live/death cell counts and the proliferation of cells based on mitochondrial and lysosomal functions [30]. In the general reduction of cell viability by more than $30 \%$ is considered as a cytotoxic effect. In this study by using two different cytotoxicity assays effects of the tested materials both on mitochondrial and lysosomal functions were evaluated.

In our previous study, we tested the cytotoxic effects of FA alone with MTT and NRU assays in L929 cells and showed that this antioxidant did not cause any cytotoxic effects [6]. Moreover, we showed FA treatment caused increases in cell proliferation compared to the negative control. Our results also demonstrate that FA plays a critical role in cell growth and development, the synthesis of nucleic acids that promote wound healing.

In recent years, many wound dressings containing different additives have been produced and tested for cytotoxicity similar to our study. Arslan et al. (2014) fabricated fibrous mats via electrospinning from solutions of polyethylene terephthalate (PET), PET/chitosan, and PET/honey at different concentrations. They evaluated the cytotoxicity of fibers by MTT and reported no cytotoxic activity. In this study after exposure to the various dilutions of extract $(25,50$, and $100 \%)$, the proliferation of L929 cells was measured and cell death and morphological damage were not observed throughout the incubation period [31]. In another study, Abouzekry et al. (2020) developed nanofibrous wound dressing by electrospinning using bee venom and pomegranate peel extract in combination with polyvinyl alcohol. According to the cytotoxicity testes on L929 cells, manufactured fibrous dressing has no cytotoxic effects [32]. Charernsriwilaiwat et al. (2012) also developed fibrous mats by electrospinning of a mixture of chitosan-ethylene diamine tetraacetic acid (CS-EDTA) $(30 / 70 \mathrm{w} / \mathrm{w})$, polyvinyl alcohol (PVA) solution (10 wt \%), and lysozyme for wound healing. Results of the cytotoxicity tests, CS-EDTA/PVA nanofibers with or without lysozyme were nontoxic at 1-10 mg / 
$\mathrm{mL}$ concentrations [33]. Kalalinia et al. (2021) produced vancomycin (VCM)-loaded hybrid chitosan/polyethylene oxide (CH/PEO) nanofibers via blend-electrospinning. According to the results of the Alamar Blue cytotoxicity testes on HDFs, there were no cytotoxic effects of any groups [34]. Bayat et al. (2019) developed nanofibers that were Bromelain-loaded chitosan for burn wounds repair. Cytotoxic activity of Ch-2\% and $4 \%$ w/v Br were tested with Alamar Blue assay. Although there are no cytotoxic effects of chitosan, Ch-2 \% w/v Br, and bromelain nanofibers, crosslinked Ch-4 \% w/v $\mathrm{Br}$ had a cytotoxic effect when compared to the control group [35]. Merrell et al. (2009) fabricated curcumin-loaded poly(caprolactone) (PCL) nanofibers by electrospinning. They directly loaded Human foreskin fibroblast cells (HFF-1) on curcumin-loaded PCL nanofibers and reported that more than $70 \%$ of cells were viable on nanofibers [36].

\section{CONCLUSIONS}

In this study, FA was successfully electrosprayed onto non-wovens surfaces. In the FT-IR analysis of the resulting materials, characteristic peaks of FA have been observed. The surface roughness of the NWs was investigated by SEM. Further, the wettability studies demonstrated electrospraying process reduces hydrophobicity. In-vitro release test showed a fast release profile of FA from the surfaces. According to NRU test results, PP SPB-sFA surfaces indicated the best cell viability value. Our findings showed FA-loaded NWs can be good candidates for wound care applications.

\section{ACKNOWLEDGEMENTS}

This study was supported by Bursa Technical University Scientific Research Projects Coordination Unit (SRP Project No. 190D003).

The authors would like to thank Mogul Textile Company or their kind donation of spun-bond and melt-blown non-woven fabrics and Bursa Technical University Central Research Laboratory (Bursa, Turkey) for the SEM and TGA analysis. The authors would like to thank Cantekin Kayk1larl1, and Metallurgical and Materials Engineering Department for pycnometer test.

\section{CONFLICT OF INTEREST}

The authors stated that there are no conflicts of interest regarding the publication of this article.

\section{REFERENCES}

[1] Hu MS, Maan ZN, Wu JC, Rennert RC, Hong WX. Tissue Engineering and Regenerative Repair in Wound Healing, Annals of Biomedical Engineering, 2014; 42: 1494-1507.

[2] Pakdemirli A, Toksöz F, Karadă̆ A, Mısırlığlu HK, Başbınar Y, Ellidokuz H, Açıkgöz O. Role of Mesenchymal Stem Cell-Derived Soluble Factors and Folic Acid in Wound Healing. Turk J Med Sci, 2019; 49: 914-921.

[3] Ammar HO, Ghorab MM, Mostafa DM, Ibrahim ES. Folic Acid Loaded Lipid Nanocarriers with Promoted Skin Antiaging and Antioxidant Efficacy, Journal of Drug Delivery Science and Technology, 2016; 31: 72-82.

[4] Jiao Z, Wang X, Yin Y, Xia J, Mei Y. Preparation and Evaluation of a Chitosan-Coated Antioxidant Liposome Containing Vitamin $\mathrm{C}$ and Folic Acid. Journal of Microencapsulation, 2018; 35(3): 272-280. 
[5] Duman N, Duman R, Tosun M, Akıcı M, Göksel E, Gökçe B, Alagöz O. Topical Folinic Acid Enhances Wound Healing in Rat Model Advances in Medical Sciences, 2018; 63(2): 347-352.

[6] Parın FN, Aydemir İnci Ç, Taner G, Yıldırım K. Co-Electrospun-Electrosprayed PVA/Folic Acid Nanofibers for Transdermal Drug Delivery: Preparation, Characterization, and in vitro Cytocompatibility. Journal of Industrial Textiles, 2021; Doi: $10.1177 / 1528083721997185$.

[7] Pagano C, Perioli L, Latterini L, Nocchetti M, Ceccarini MR, Marani M, Ramella D, Ricci M. Folic Acid-Layered Double Hydroxides Hybrids in Skin Formulations: Technological, Photochemical and in vitro Cytotoxicity on Human Keratinocytes and Fibroblasts. Applied Clay Science, 2019; 168: 382-395.

[8] Zhao M,Zhou J, Chen Y,Yuan L, Yuan M, Zhang X, Hu Y, Yu H. Folic Acid Promotes Wound Healing in Diabetic Mice by Suppression of Oxidative Stress, J Nutr Sci Vitamin, 2018; 64(1): 26-33.

[9] Khan S, Rahman SZ, Ahad A. Local Drug Delivery of Folic Acid Promotes Oral Mucosal Wound Healing. Journal of Dental Sciences, 2021; 16(1): 532-533.

[10] Camacho DH, Uy SJY, Cabrera MJF, Lobregas MOS, Fajardo TJMC. Encapsulation of Folic Acid in Copper-Alginate Hydrogels and It's Slow in vitro Release in Physiological pH Condition. Food Research International, 2019; 119: 15-22.

[11] Mallakpour S, HatamiM. Highly Capable and Cost-Effective Chitosan Nanocomposite Films Containing Folic Acid-Functionalized Layered Double Hydroxide and Their in Vitro Bioactivity Performance. Materials Chemistry and Physics2020;250:123044.

[12] Acevedo-Fani A, Soliva-Fortuny R, Martín-BellosoO. Photo-protection and Controlled Release of Folic Acid using Edible Alginate/Chitosan Nanolaminates. Journal of Food Engineering, 2018; 229:72-82

[13] Fonsecaa LM, Crizela RL, Silvaa FT, VazFontesa MR, Zavarezea ER, Guerra Dias AR. Starch Nanofibers as Vehicles for Folic Acid Supplementation: Thermal Treatment, UVA İradiation, and in vitro Simulation of Digestion, Journal of the Science of Food and Agriculture, 2020; https://doi.org/10.1002/jsfa.10809.

[14] Şimşek M, Rzayev ZMO, Bunyatova U, Khalilova S, TürkM. Multifunctional Electrospun Biocompatible Nanofiber Composites from Water Dispersion Blends of Folic Acid Conjugated PVP/Dextran/ODA-MMT Nanocomposites and Their Responses to Vero cells. Hacettepe Journal of Biology and Chemistry, 2016; 44(4):441-450.

[15] Bock N, Dargaville TR,Woodruf MA. Electrospraying of Polymers with Therapeutic Molecules: State of The Art, Progress in Polymer Science, 2012; 37: 1510-1551. 
[16] He L, Zhao Y, Tian L, Ramakrishna S. Nanobiomaterials: Classification, Fabrication and Biomedical Applications. I., Wang, M. Ramalingam, X. Kong, L. Zhao (Eds.), Electrospraying and Electrospinning for Nanobiomaterial Fabrication, 2017; (1st ed., Vol. 6, pp.143-163). New York : Wiley-VCH.

[17] Alehosseini A, Ghorani B, Sarabi-Jamab M, Tucker N. Principles of electrospraying: A New Approach in Protection of Bioactive Compounds in Foods. Critical Reviews in Food Science and Nutrition, 2017; 58(14): 2346-2363.

[18] Madhaiyan K, Sridhar R, Sundarrajan S, Venugopal JR, Ramakrishna S. Vitamin B12 Loaded Polycaprolactone Nanofibers: A Novel Transdermal Route for The Water Soluble Energy Supplement Delivery. International Journal of Pharmaceutics, 2013; 444(1-2): 70-76.

[19] Parın FN, Yıldırım K. Preparation and Characterization of Vitamin Loaded Electrospun Nanofibers as Promising Transdermal Patches. Fibres \& Textiles in Eastern Europe, 2021; 1(145): 17-25.

[20] Ekabutr P, Chuysinuan P, Suksamrarn S, Sukhumsirichart W, Hongmanee P, Supaphol P. Development of Antituberculosis Melt-blown Polypropylene Filters Coated with Mangosteen Extracts for Medical Face Mask Applications. Polymer Bulletin, 2019; 76: 1985-2004.

[21] Jung JH, Lee JE, Bae G. Use of Electrosprayed Sophora Flavescens Natural-Product Nanoparticles for Antimicrobial air Filtration. Journal of Aerosol Science, 2013; 57: 185-193.

[22] Xiao X, Chen F, Wei Q, Wu N. Surface Modification of Polyester Nonwoven Fabrics by $\mathrm{Al}_{2} \mathrm{O}_{3}$ Sol-gel Coating, Journal of Coatings Technology and Research, 2009; 6(4): 537-541.

[23] Alma MH, Yazıcı M, Yıldırım B, Salan, T, Tiyek İ. Spunbond Dokusuz Tekstil Yüzeyi Üzerine Elektro Çekim Yöntemi ile Nano Boyutta Grafen Kaplanması ve Karakterizasyonu. Tekstil ve Mühendis, 2017; 24(108): 243-253.

[24] Delaviz Y, Santerre JP, Cvitkovitch DG. Infection Resistant Biomaterials, Biomaterials and Medical Device-Associated Infections, 2015; 11: 223-254.

[25] Berendjchi A, Ali R, Yousefi A, Yazdanshenas ME. Surface Characteristics of Coated Polyester Fabric with Reduced Graphene Oxide and Polypyrrole, Applied Surface Science, 2016; 367: 36-42.

[26] Ma ZW, Kotaki M, Yong T, He W, Ramakrishna S. Surface Engineering of Electrospun Polyethylene Terephthalate (PET) Nanofibers Towards Development of a New Material For Blood Vessel Engineering. Biomaterials, 2005; 26: 2527-2536. 
[27] Sreedhara SS, Tata NR. A Novel Method for Measurement of Porosity in Nanofiber Mat using Pycnometer in Filtration. Journal of Engineered Fibers and Fabrics, 2013; 8(4).

[28] Gültekin E, Çelik Hİ, Nohut, S, Elma SK. Predicting Air Permeability and Porosity of Nonwovens with Image Processing and Artificial Intelligence Methods. The Journal of the Textile Institute, 2020; 111(11): 1641-1651.

[29] Weyermann J, Lochmann, D, Zimmer A. A Practicalnote on Theuse of Cytotoxicity Assays. International Journal of Pharmaceutics, 2005; 288 (2): 369-376.

[30] Melo PS, de Medeiros Cavalcante HM, Barbosa-Filho JM, de Fátima Formiga Melo Diniz M, de Medeiros IA, Haun M. Warifteine and Milonine, Alkaloids Isolated from Cissampe Lossympodialis Eichl: Cytotoxicity on Rathepatocyte Culture and in V79 Cells. Toxicology Letters, 2003; 142 (1-2):143-151.

[31] Arslan A, Şimşek M, Aldemir SD, Kazaroğlu NM, Gümüşderelioğlu, M. Honey-Based PET or PET/Chitosan Fibrous Wound Dressings: Effect of Honey on Electrospinning Process. Journal of Biomaterials Science, Polymer Edition, 2014; 25(10): 999-1012.

[32] Abouzekry S, Abdellatif A, Azzazy Hassan. Fabrication of Pomegranate/Honey Nanofibers for use As Antibacterial Wound Dressings. Wound Medicine, 2020; 28: 100181.

[33] Charernsriwilaiwat N, Opanasopit P, Rojanarata T, Ngawhirunpat T. LysozymeLoaded, Electrospun Chitosan-Based Nanofiber Mats for Wound Healing. International Journal of Pharmaceutics, 2012; 427(2): 379-384.

[34] Kalalinia F, Taherzadeh Z, Jirofti N, Amiri N, Foroghinia N, Beheshti M, Fazly B, Bibi S, Hashemi M, Shahroudi A, Pishavar E, Tabassi S, Movaffagh J. Evaluation of Wound Healing Efficiency of Vancomycin-Loaded Electrospun Chitosan/Poly Ethylene Oxide Nanofibers in Full Thickness Wound Model of Rat. International Journal of Biological Macromolecules, 2021; 177. 10.1016/j.ijbiomac.2021.01.209.

[35] Bayat S, Amiri N, Pishavar E, Kalalinia F, Movaffagh J, Hahsemi M. BromelainLoaded Chitosan Nanofibers Prepared by Electrospinning Method for Burn Wound Healing in Animal Models. Life Sciences, 2019; 229. 10.1016/j.lfs.2019.05.028.

[36] Merrell JG, McLaughlin SW, Tie L, Laurencin CT, Chen AF, Nair LS. Curcuminloaded poly(epsilon-caprolactone) nanofibres: diabetic wound dressing with antioxidant and anti-inflammatory properties. Clinical and experimental pharmacology \& Physiology, 2009; 36(12): 1149-1156. 